\title{
Preparation for Lower Port Integration Engineering for ITER Diagnostic Systems in JADA*)
}

\author{
Sin-iti KITAZAWA, Toshiyuki MARUYAMA, Hiroaki OGAWA, Kiyoshi ITAMI and \\ Natalia CASAL ${ }^{1)}$ \\ Naka Fusion Institute, Japan Atomic Energy Agency, JAEA, Naka 311-0193, Japan \\ 1) ITER Organization, Route de Vinon sur Verdon, St Paul-lez-Durance, France
}

(Received 18 November 2014 / Accepted 12 March 2015)

\begin{abstract}
In ITER, there are various ports at the upper, equatorial, and lower levels, which serve various purposes such as evacuation, heating, remote handling, and diagnostics. Since several diagnostics will be integrated in Lower Port \#2 (LP\#02), its procurement is in the scope of diagnostics. The integration engineering activities of LP\#02 are included in the scope of Japan Domestic Agency (JADA) procurement because the dominant component, the Divertor Impurity Monitor (DIM), is procured by JADA. The components in the LP\#02 procurement package are the diagnostic racks assembly, interspace assembly, port cell assembly and tooling. The integration of these components must minimize impacts on the divertor exchange procedure, and requires the assemblies to be manufactured as fully integrated components and interfaces. In the current status, which is between the conceptual design and signature of the procurement arrangement, JADA identified technical issues and implemented thermal and structural analyses within the specified design conditions.
\end{abstract}

(c) 2015 The Japan Society of Plasma Science and Nuclear Fusion Research

Keywords: ITER, lower port, diagnostics, integration engineering, divertor impurity monitor

DOI: $10.1585 /$ pfr. 10.3402044

\section{Introduction}

The procurements in the ITER project are mainly inkind; therefore each domestic agency (DA) designs, manufactures, and tests the components under the oversight of the ITER organization (IO) throughout the construction of ITER. Assembly and commissioning at the ITER site are within the scope of the IO. For such an unprecedented and complex international procedure, extraordinary design reviews, verifications, inspections, and tests are required.

Forty-four ports around the ITER vacuum vessel provide access for remote handling operations, diagnostic systems, heating, and vacuum systems: 18 upper ports, 17 equatorial ports, and 9 lower ports. The lower ports are also called divertor ports because of their close proximity to the divertor and since they are used to insert and exchange divertor cassettes [1]. 10 upper ports, 8 equatorial ports, and 3 lower ports are the so-called diagnostics ports. The diagnostic lower ports are used for the aforementioned installation of divertor cassettes by remote handling and for diagnostics after installation. For ITER, the procurements for diagnostic lower ports engineering belong not to the vacuum vessel, but to the diagnostics because the components on the port structures are associated with the diagnostic instruments in these ports. Japan Domestic Agency (JADA) is responsible for divertor impurity monitor (DIM) procurement [2], therefore JADA is also

author's e-mail: kitazawa.siniti@jaea.go.jp

*) This article is based on the presentation at the 24th International Toki Conference (ITC24). responsible for the integration engineering of the lower port \#02 (LP\#02) whose main component is the DIM. The other two lower ports \#08 and \#14 will be integrated by the Russian DA (RFDA) and the IO. The conceptual design (CD) review meeting for common lower port systems was held on the 7th and 8th October 2014 at the ITER site, and the procurement arrangement (PA) documents are about to be signed. In this paper, an overview of the systems of LP\#02 and prospective scientific and engineering solutions for the functions and components of the system are described.

\section{Scope}

In the ITER project, there are two aspect of scope breakdown: one for work and the other for plant. There are two approaches for LP\#02, by activities and components.

\subsection{LP\#02 integration engineering activity}

In the scope of the LP\#02 system integration engineering, the main activities are design, manufacturing, and integration. For the design of the ITER systems, there are three phases: conceptual design (CD), preliminary design (PD), and final design (FD). The procurement of the LP\#02 system is categorized as a "detailed design"; therefore the IO has responsibility during the $\mathrm{CD}$ phase until the PA is signed, and JADA has responsibility during the PD and FD phases. Components are procured in-kind, that is they are manufactured by the responsible DA. The integration of 


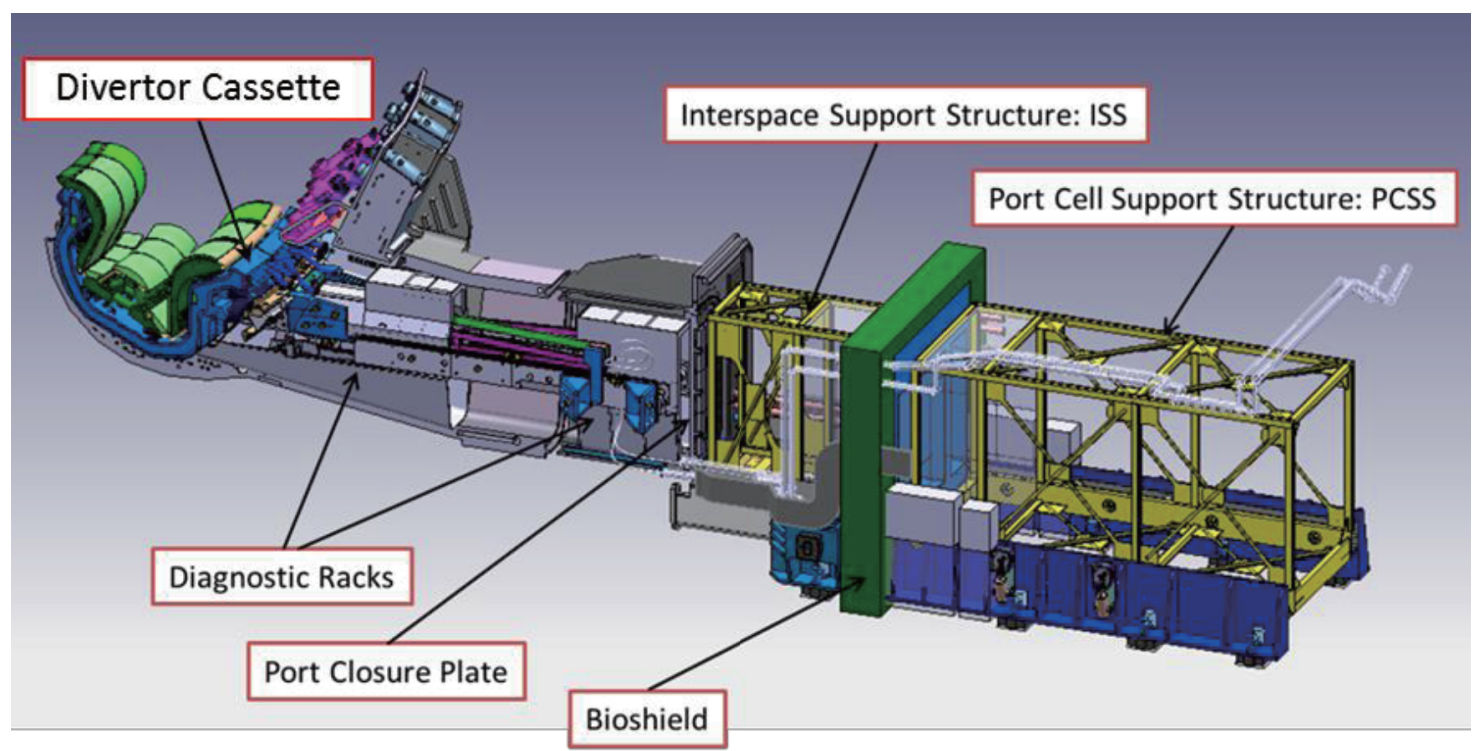

Fig. 1 Schematic drawing of ITER Diagnostic LP\#02. The divertor cassettes and divertor associated components are not included in the scope.

components includes on-site testing, installation. Environment tests in port plug test facility are planned but the details have not been decided upon yet.

\subsection{LP\#02 system components}

This section contains a brief overview of LP\#02. The details of the lower port components and the racks are described in [1] and [3], respectively.

A schematic drawing of the ITER diagnostic LP\#02 is shown in Fig. 1. The scope of the LP\#02 system components includes a diagnostic rack installed in vacuum; interspace support structures (ISS) installed outside of the vacuum; and port cell support structures (PCSS). The boundary between the diagnostic rack and ISS is a vacuum boundary where the port closure plate is installed. Bioshields will be installed in the intermediate space between the ISS and PCSS, to protect the PCSS from radiation leakage.

\section{Functionality}

An investigation of inherent functions is very important for developing the ITER system design to reduce the impact of potential technical risks on the operation of the machine. There are different functional analyses of LP\#02, such as a risk assessment for procurement, and a RAMI (reliability, availability, maintainability, and inspectability) analysis for technical risk reduction [4]. A functional breakdown of the LP\#02 system is summarized in Table 1. The top function A- 0 is derived from the ITER Project requirements. The 4 main functions, A1, A2, A3 and A4 relate to the rack, interspace, port cell and signal processing, respectively. The second tier and lower level functions will be revised and defined as the design progresses.

\section{Interfaces}

The technical interfaces of LP\#02 integration engineering are very complicated and spans over a wide range of fields. The technical interfaces are divided into internal interfaces within diagnostics and external interfaces within other project breakdown structures.

For the internal interfaces, the equipment to be integrated in LP\#02 is procured by the IO and DAs. The details are summarized in Table 2. The integration of those systems into each structure is the most critical issue in engineering LP\#02.

For the external interfaces, the components are included in the vacuum vessel, divertor, machine assembly and tooling, remote handling system, cooling water system, vacuum, central Instrumentation and Controls (I\&C) system, tokamak building, liquid and gas distribution, radwaste treatment and storage.

\section{Predesign Analyses}

Many analyses of the system as a whole such as thermal, structural, feasibility, and nuclear are necessary to implement the preliminary design of LP\#02 engineering. These analyses were conducted to ensure that the rack structure could be manufactured satisfactory with the requirement in JADA.

We performed thermal analyses of LP\#02 to evaluate the space distribution of thermal stress in the fundamental design. The divertor cassette shields the plasma heating, and then the thermal load onto LP\#02 is only nuclear heating. The thermal stress in the rack has more effect on the requirement than that of interspace and port cell structures. [5] The shield on the rack, which has the highest thermal load of all the components, was evaluated by a 
Table 1 Functional breakdown of the ITER LP\#02 Integration Engineering.

A0 To integrate the Diagnostic Racks, Interspace, Port Cell assemblies and the Instrumentation and Controls (I\&C)

A1 To provide Diagnostic Racks assembly functions

A11 To host in-vessel components of tenant diagnostics and other components in the Diagnostic Rack Assembly

A12 To maintain structural integrity withstanding all the loads (electromagnetic, thermal, nuclear, seismic, etc.) in the Diagnostic Rack Assembly

A13 To contribute to shielding the rest of the machine from plasma radiation in the Diagnostic Rack

A14 To seal the primary vacuum at the port

A15 To allow water-based regulation of the temperature of the Diagnostic Rack structures

A16 To measure environmental parameters (temperature) in the Diagnostics Rack

A17 To contribute to maintenance operations for the Diagnostics Rack

A2 To provide Interspace assembly functions

A21 To host components of tenant diagnostics and other components in the Interspace Assembly

A22 To withstand thermal, EM, nuclear, seismic and gravity loads in the Interspace

A23 To manage the allocated nuclear dose in the Interspace

A24 To contribute to maintenance operations for the Interspace Assembly

A3 To provide Port Cell assembly functions

A31 To host tenant diagnostics components and other components in the Port Cell Assembly

A32 To withstand thermal, EM, nuclear, seismic and gravity loads in the Port Cell

A33 To manage the nuclear dose in the Port Cell

A34 To contribute to maintenance operations for the Port Cell Assembly

A4 To provide I\&C functions

A41 To provide Temperature measurements of the Port Structures

A42 To provide Electrical heater with temperature control during baking of windows

A43 To provide Spare input measurement channel

Table 2 Diagnostic systems of LP\#2.

\begin{tabular}{|c|c|}
\hline System & Procured by \\
\hline Divertor equilibrium sensors & \multirow{5}{*}{ Europe DA } \\
\hline Divertor shunts & \\
\hline Divertor Rogowski coils & \\
\hline Divertor toroidal coils & \\
\hline Inner divertor thermocouples & \\
\hline Divertor neutron flux monitors & Russia DA \\
\hline Langmuir probes & China DA \\
\hline Divertor impurity monitor & \multirow{2}{*}{ Japan DA } \\
\hline Outer divertor thermocouples & \\
\hline Pressure gauges & $\mathrm{IO}$ \\
\hline
\end{tabular}

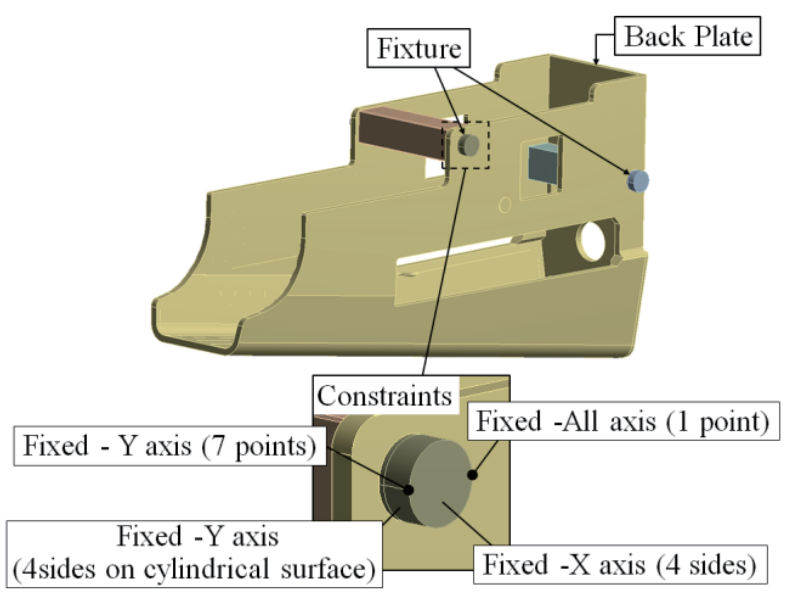

Fig. 2 Constraints of the rack structure for the estimation.

steady-state thermal analysis and a static structural analysis. The finite element method (FEM) was adopted for the numerical analysis.

The conditions are summarized in brief. The thermal load was estimated from Iida's works [5] with some margins and declines; $0.8 \mathrm{MW} / \mathrm{m}^{3}$ from the tip to $1 \mathrm{~m}$, $0.08 \mathrm{MW} / \mathrm{m}^{3}$ from 1 to $1.5 \mathrm{~m}$, and $0.01 \mathrm{MW} / \mathrm{m}^{3}$ over $1.5 \mathrm{~m}$. The cooling water flow rate is $20 \mathrm{l} / \mathrm{min}$ at a temperature of $70^{\circ}$ with a hydraulic pressure of $4 \mathrm{MPa}$. The axes are on the ITER coordinate system: $\mathrm{X}$ for toroidal, $\mathrm{Y}$ for vertical, and $\mathrm{Z}$ for the radial direction. However the calculation was performed in Cartesian, because the he rack structure shapes rectangular. The constraints of the static structural analysis are that one point is fixed on the surface, four sides are fixed in $\mathrm{X}$ direction and seven points are fixed in $\mathrm{Y}$ direction. Figure 2 shows a schematic drawing of the constraints.

A thermal analysis of the rack structure of SUS316 is shown in Fig. 3. The effect on thermal stress was compared in the inherent model without cooling (a) and a model with water cooling pipes in the back plate (b). The highest stress $628 \mathrm{MPa}$ was lowered to $198 \mathrm{MPa}$ by water cooling. The highest stress, appeared at the fixture of the rack and vacuum vessel, was produced from their displacements against the binding force. This analysis shows that some kind of cooling system is required at the back plate of the rack, even though the thermal load at the back plate is lower than the proof stress of SUS316, 205 MPa. Therefore, it was shown that cooling is required.

A valuable instance of an analysis by applying magnetic force for the cooling structure on the rack is shown in Fig. 4. Four sides are fixed downwards vertically with a $50 \mathrm{~mm}$ wide cylindrical surface as shown in Fig. 2. The other conditions are the same as the analysis for thermal load. The magnetic field was assumed to be a disruption [6].

The analyses and evaluation, in the electromagnetic force loading conditions, showed that excessive stress may 

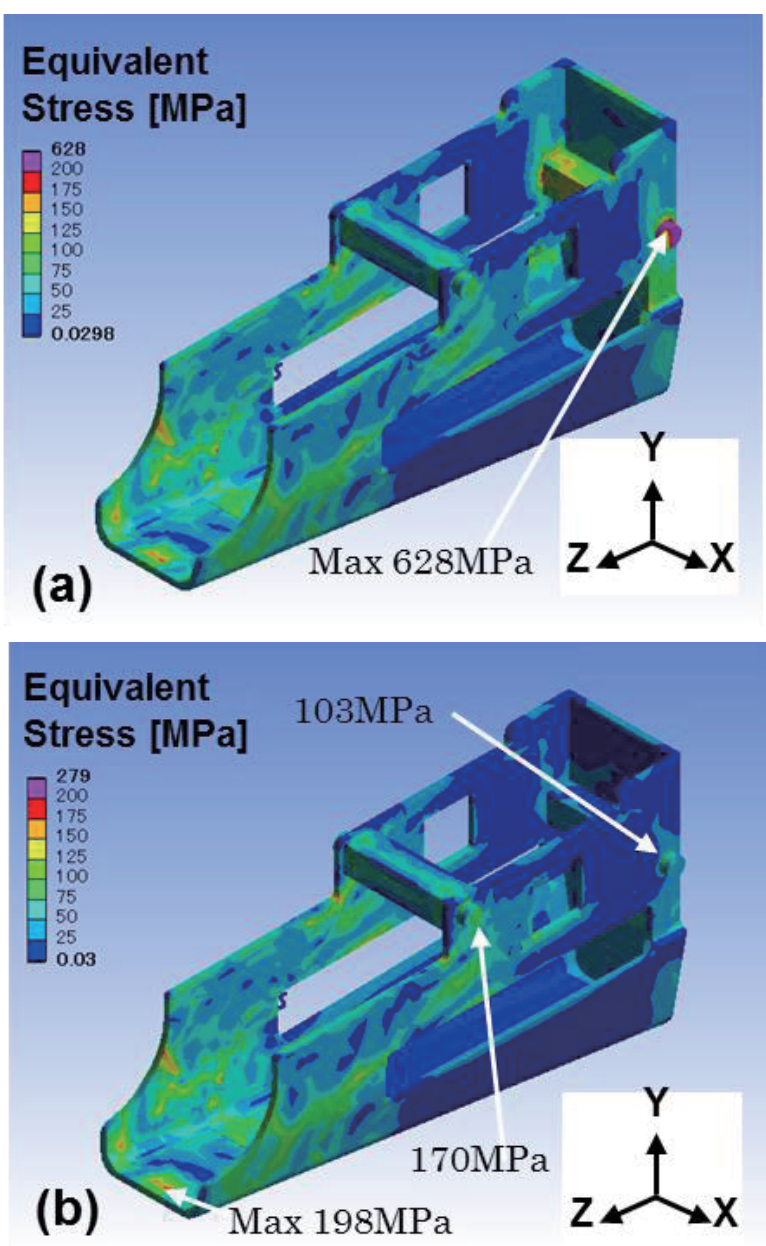

Fig. 3 FEM analysis of thermal stress on rack support structure. Without (a) and with (b) a water cooling line in the back plate.

be generated at the tip of the inner rack. This has been attributed to the given local load conditions. The exact distributions of electromagnetic force loading conditions are required in order to evaluate the design of the rack structure properly. In addition, evaluation of conditions such as superposition of its own weight and nuclear heat generation load are also necessary in the future.

\section{Summary}

In the ITER project, JADA will procure the LP\#02 integration engineering that must satisfy all ITER requirements. The present status of the design is between CD and PA signature. The scope and the various interfaces have been prepared for the PA to be signed. Detailed specifications must be prepared to proceed with the design. The

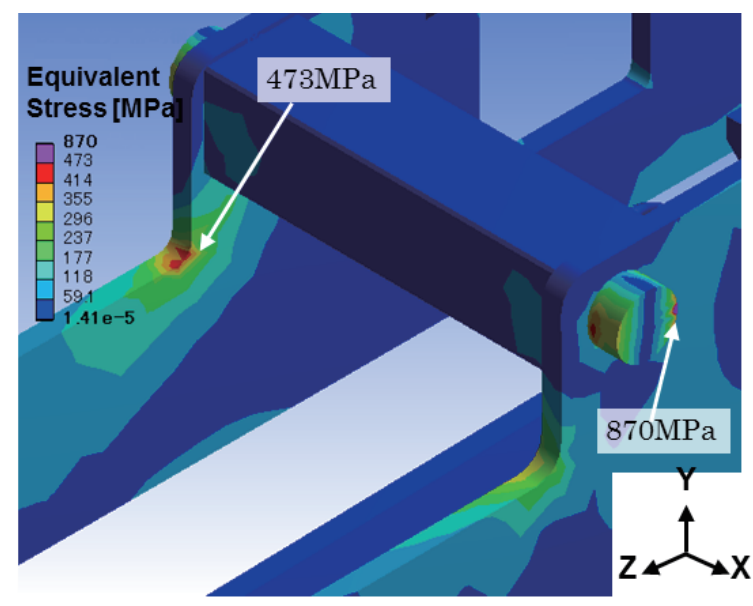

Fig. 4 FEM analysis of stress by magnetic force on rack support structure. Two points with peak values of the stress are indicated.

LP\#02 system functional breakdown and system overview was investigated for the $\mathrm{CD}$, however further unique properties must be investigated. There are also still many analyses that need to be performed to define the specifications so the design can proceed to the next step in the design process. The procurement for a suitable LP\#02 system under these complex conditions while keeping within schedule has proven to be challenging.

\section{Acknowledgements}

The authors acknowledge the fruitful discussions about the diagnostics with T. Yamamoto and T. Sugie and other JAEA colleagues including N. Duncan for his help with making this manuscript. The authors would also like to thank V. Udintsev and M. Walsh and other IO colleagues for their helpful exchange of information.

\section{Disclaimer}

The views and opinions expressed herein do not necessarily reflect those of the ITER Organization.

[1] N. Casal et al., "Design and integration of lower ports for ITER diagnostic systems", submitted to Fusion Eng. Des.

[2] H. Ogawa et al., Fusion Eng. Des. 83, 1405 (2008).

[3] V.S. Udintsev et al., Fusion Eng. Des. 88, 1215 (2013).

[4] S. Kitazawa et al., Plasma Fusion Res. 9, 3405049 (2014).

[5] H. Iida et al., Nuclear Analysis Report. G 73 DDD 2 W0.2, NAG-201-NAR, July 2004.

[6] ITER Physics Basis, Nucl. Fusion 39, 2137 (1999). 